\title{
Purwarupa Sistem Pendataan Pengunjung dan Pengendalian Perangkat Laboratorium Dalam Pengembangan Smart Campus
}

\author{
Heny Pratiwi ${ }^{\mathrm{a}}$, Alfa Satyaputra ${ }^{\mathrm{b}}$, Arnold Aribowo ${ }^{\mathrm{c}}$ \\ ${ }^{a}$ Sistim Komputer, fakultas ilmu komputer, Universitas Pelita Harapan, 06hnmay@ gmail.com \\ ${ }^{\mathrm{b}}$ Sistim Komputer, fakultas ilmu komputer, Universitas Pelita Harapan, alfa.satyaputra@uph.edu \\ ${ }^{\mathrm{c}}$ Sistim Komputer, fakultas ilmu komputer, Universitas Pelita Harapan, arnold.aribowo@uph.edu
}

\begin{abstract}
The laboratory visitors data collection system serves as a timestamp data collection of laboratory visitors, and the control system is set for controlling electrical devices such as air conditioners, lights, and door locks inside the laboratory room according to the visitors amount, both are integrated as one system for implementing the development of Smart Campus and supporting conveniences and security for Lecturers, staff and students. The system uses hardware such as door lock solenoid, relay board, RFID reader, serial-cables and Arduino microcontrollers. Some software are used such as Node.js scripts (JavaScript runtime environment) as the central logic and communication, one Arduino microcontroller programmed with Arduino software program, and another Arduino microcontroller is embedded with firmware Firmata and application software such as server XAMPP for web pages using Bootstrap framework and Javascript library such as AngularJS, JQuery and Javascript Bootstrap. Furthermore, MySQL is used as a database by using a serial protocol, and then WebSocket and Johnny-Five Framework are used as a complement system solution. Overall integration of the systems is expected to run smoothly as designed.
\end{abstract}

Keywords: Node.Js, MySQL, Websocket, Firmata, Serial Communication

\begin{abstract}
Abstrak
Sistem pendataan pengunjung laboratorium berfungsi sebagai pendataan waktu keluar-masuk pengunjung laboratorium, sedangkan sistem pengendali perangkat mengendalikan perangkat kelistrikan seperti pendingin ruangan, lampu, dan kunci pintu, semua terintegrasi sebagai satu sistem sebagai implementasi dari pengembangan Smart Campus yaitu kampus yang memberikan kenyamanan dan keamanan bagi dosen, staff dan mahasiswa. Hardware yang digunakan adalah solenoid lock door, papan relay, pembaca RFID, kabel serial dan dua unit mikrokontroler Arduino, sedangkan software yang digunakan adalah skrip Node.js (JavaScript runtime environment) sebagai pusat logika dan komunikasi, program Arduino pada mikrokontroler Arduino pertama, dan firmware Firmata pada mikrokontroler Arduino kedua, dan aplikasi XAMPP sebagai server halaman web yang menggunakan framework Bootstrap, serta library Javascript diantaranya AngularJS, JQuery dan Javascript Bootstrap. MySQL, sebagai basis data, menggunakan serial protocol. Selanjutnya pelengkap solusi sistem adalah websocket dan Johnny-Five Framework. Hasil keluaran integrasi seluruh sistem sesuai rancangan adalah keberhasilan yang diharapkan.
\end{abstract}

Kata Kunci: Node.Js, MySQL, Websocket, Firmata, komunikasi serial

(C) 2017 Jurnal RESTI

\section{Pendahuluan}

Automasi adalah satu sistem solusi untuk segala aktifitas operasi yang memiliki sifat repetitif yang dilakukan secara manual. Solusi dengan sistem automasi memberi kenyamanan, kemudahan dan kepraktisan buat para pemakai yang secara rutin harus melakukan aktifitas tersebut. Salah satu cara penerapan sistem automasi ini adalah dengan menggunakan Microcontroller.
Sistem pendataan pengunjung ruang laboratorium, antarmuka dan robotika, di gedung B ruang 241 Universitas Pelita Harapan, Lippo Karawaci, dipilih sebagai tempat untuk penerapan sistim rancangan automasi, dengan alasan operasional dan aktifitas diruang tersebut masih dilakukan secara manual. Pendataan pengunjung dijadikan sebagai masukan untuk pengendalian perangkat kelistrikan ruang laboratorium. Selanjutnya penerapan sistem automasi pendataan pengunjung, diharapkan bisa melayani 
kenyamanan para pengunjung yang sering lupa mengisi sebelumnya selesai. Namun pada Node.js proses tidak buku daftar tamu setiap hari. Selama waktu perlu menunggu proses sebelumnya selesai. [2][7] operasional, sistem melakukan pendataan setiap pengunjung yang keluar-masuk ruang laboratorium 2.3 Websocket dan Firmata tersebut. Selain bisa membantu kenyamanan pengunjung, sistem ini juga bisa mengurangi biaya konsumsi enersi listrik. Beberapa bagian sistem dan komponen membutuhkan rancang-bangun hardware dan software, dengan pengujian keduanya secara terpisah. Pengujian integrasi keseluruhan system merupakan tahap akhir.

WebSocket pertama kali muncul pada HTML5, yang memungkinkan adanya komunikasi antara server dan web browser secara real-time. Untuk memulai sebuah koneksi WebSocket, pertama - tama client mengirimkan permintaan handshake kemudian server membalas dengan sebuah respon. Ketika sebuah koneksi telah tercipta, maka komunikasi awal yang berbasis HTTP Solenoid lock door, papan relay, pembaca RFID, kabel berubah menjadi komunikasi full-duplex [2:13]. serial, dan dua microcontroller Arduino adalah hardware yang dipakai. Sedangkan software yang di rancang-bangun menggunakan bahasa pemrograman Node.js sebagai pusat logika dan komunikasi, bahasa pemrograman Arduino pada microcontroller Arduino pertama, dan bahasa pemrograman firmware Firmata microcontroller Arduino kedua, serta aplikasi XAMPP sebagai server pada webpage. Sedangkan webpage harus dibangun menggunakan framework Bootstrap dan beberapa library Javascript seperti AngularJS, JQuery dan Javascript Bootstrap, selanjutnya pendataan menggunakan MySQL. Dibutuhkan pula media protokol komunikasi antara Node.js, firmware Firmata, halaman web dan basis-data pendataan dengan menggunakan protokol serial, websocket, dan Johnny-Five.

\section{Tinjauan Pustaka}

\subsection{MySQL}

Firmata adalah sebuah protokol komunikasi antara software komputer dengan mikrokontroler. Protokol dapat diimplementasi di dalam firmware dari sebuah mikrokontroler atau pada paket perangkat lunak (software package). Secara teori protokol Firmata dapat diimplementasi pada semua jenis mikrokontroler. Namun, pada saat ini implementasi terlengkap terdapat pada mikrokontroler Arduino, termasuk mikrokontroler yang kompatibel dengan arduino [5].

\subsection{Komunikasi Serial}

Komunikasi serial adalah proses pengiriman data satu bit secara berurutan dalam satu satuan waktu, melalui sebuah saluran komunikasi atau computer bus. Setiap data yang dikirimkan akan dimulai dengan sebuah start-bit untuk menandakan awal dari suatu data dan diakhiri dengan stop-bit untuk menandakan data berakhir. Setiap perangkat yang menggunakan komunikasi serial harus memiliki kesepakatan dimana

Basis data (database) adalah sekumpulan data yang kedua perangkat menggunakan pengaturan kecepatan diatur dengan satu system pengaturan, dan disimpan dan paritas yang sama [14][15].

dalam/dengan format yang didefinsikan, kemudian strukturnya ditentukan oleh metadata. Ada beberapa model basis data yang dapat digunakan. Pada penelitian ini digunakan basis data MySQL, yang mengimplementasi model relational. Model ini merupakan model yang paling banyak digunakan karena memiliki beberapa kemudahan dibandingkan dengan model basis data lainnya, seperti: data dapat ditambah dan dikurangi tanpa merubah struktur data secara keseluruhan dan sebuah data dapat memiliki lebih dari satu parent [11] [15].

\subsection{Node.js}

\section{Metodologi Penelitian}

Penelitian ini diawali dengan studi pustaka untuk mengumpulkan data dan informasi dari sumber informasi yang ada, baik melalui e-book, buku-buku, artikel, atau data-data lain dari internet yang berhubungan dengan permasalahan solenoid lock door, papan relay, pembaca RFID, kabel serial dan microcontroller Arduino, Node.js, firmware Firmata, aplikasi XAMPP, framework Bootstrap, library Javascript seperti AngularJS, JQuery dan Javascript Bootstrap, dan MySQL. Data dan informasi yang didapat kemudian dibaca dan dievaluasi sebelum Node.js merupakan platform yang dibuat dari Chrome diterapkan ke dalam sistem yang ingin dibangun. JavaScript runtime yang berguna untuk membangun Selanjutnya, dilakukan rancang bangun hardware atau aplikasi jaringan dengan cepat dan scalable. Node.js perangkat keras, dan dilakukan troubleshooting untuk menggunakan model event-driven, non-blocking I/O setiap komponen, berikutnya juga dilakukan analisis, yang membuat Node.js ringan dan efisien, tepat untuk dan perancangan software atau perangkat lunak yang pembuatan aplikasi real-time. Hal ini menjadi salah dibangun untuk mendapatkan keluaran yang tepat satu kelebihan dari Node.js karena pada model bahasa setelah pengujian.

pemrograman umumnya contohnya sekuensial, suatu proses hanya dapat dikerjakan setelah proses

Jurnal RESTI (Rekayasa Sistem dan Teknologi Informasi) Vol. 1 No. 1 (2017) 50 - 57 


\section{Hasil dan Pembahasan}

Sistem ini merupakan purwarupa atau prototype, sehingga perangkat laboratorium yang digunakan dalam penelitian ini bisa menjadi framework untuk direalisasikan kemudian hari, dan sudah menggunakan komponen yang mewakili produk nyata. Bagan purwarupa sistem yang dirancang dapat dilihat pada Gambar 1

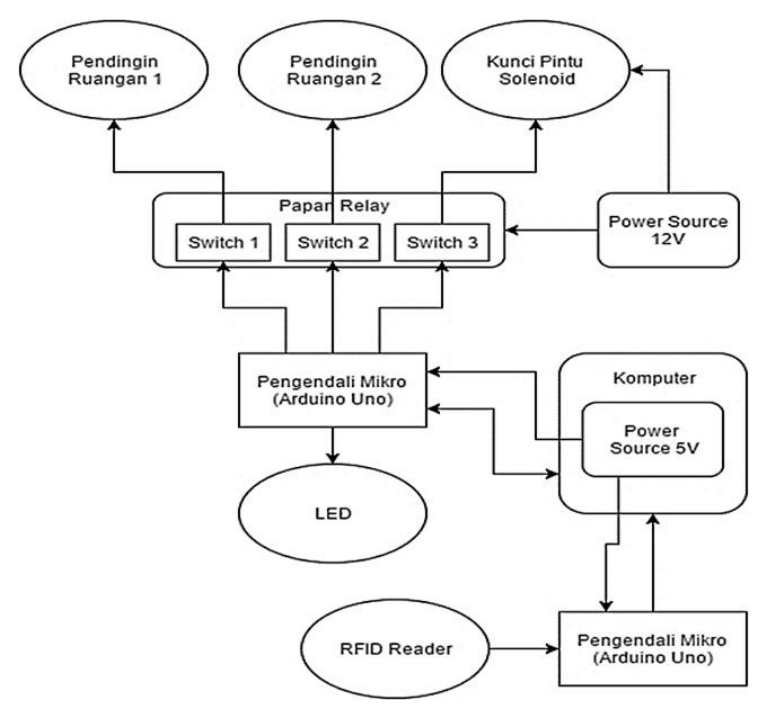

Gambar 1. Prototipe Sistem Yang Dirancang

Pada perangkat pertama yaitu pendingin ruangan atau air conditioner menggunakan sebuah relay, yang pada aplikasi system dihubungkan ke pendingin ruangan tersebut. Karena ada tiga buah relay yang digunakan, maka sebuah papan yang memuat beberapa relay bisa membantu memudahkan proses aplikasi. Relay pertama dan kedua digunakan untuk simulasi mesin pendingin ruangan. Relay ketiga dihubungkan ke sebuah pengunci pintu solenoid. Sedangkan sumber tenaga relay tersebut didapatkan dari dua buah baterai jenis ukuran AA yang memiliki daya 12 Volt.

Perangkat kedua adalah dimaksudkan untuk mewakili lampu penerangan ruang, dalam hal ini digantikan oleh enam buah $L E D$ yang dirangkai membentuk tiga baris, setiap baris terdiri dari dua buah LED (dirancang seperti ruang laboratorium UPH gedung B ruang 241) dan dimaksudkan untuk mensimulasikan tiga baris lampu di ruang laboratorium B241. Setiap pin arus positif pada $L E D$ dihubungkan ke sebuah pin digital pada mikrokontroler Arduino untuk supaya LED tersebut mendapat sumber tenaga listrik dari Arduino tersebut dan sekaligus pengendalian $L E D$ juga bisa dilakukan melalui Arduino. Sedangkan semua pin arus negatif atau ground pada $L E D$ dihubungkan secara paralel pada breadboard dan kemudian dihubungkan ke pin ground pada Arduino.

Perangkat yang utama dalam sistem pendataan dan pengendalian seluruh system, adalah sebuah komputer.
Selain komputer tersebut menjadi sumber tenaga listrik bagi mikrokontroler Arduino, komputer tersebut menjadi penting karena berfungsi sebagai server, yaitu server Node.js. yang sudah di unduh dan tersimpan dalam komputer tersebut. Server ini selanjutnya berfungsi sebagai pusat pengontrol, pengolahan data, dan mengelola komunikasi antara mikrokontroler Arduino, halaman web dan basis data.

Dalam penelitian ini melibatkan juga basis-data, halaman web, dan server Apache. Basis-data berfungsi untuk mengorganisasi data yang masuk. Halaman web diperlukan untuk memonitor aplikasi secara mobile, sedangkan server Apache yang sangat umum dipakai untuk halaman web dan basis data. Mikrokontroler yang digunakan untuk aplikasi sistim ini sebanyak dua buah Arduino Uno. Mikrokontroler Arduino Uno yang pertama berfungsi sebagai pengendali relay dan $L E D$, sedangkan Arduino Uno yang kedua berfungsi sebagai penerima masukan data dari RFID reader. Pada aplikasi sistim ini juga perlu digunakan firmware Firmata yang berfungsi untuk menjembatani kondisi pin Arduino Uno supaya dapat dikendalikan oleh server Node.js. Namun firmware tersebut tidak mendukung library MFRC522, yang dihubungkan ke Arduino dimaksudkan sebagai media komunikasi dengan modul RFID reader, untuk mengatasi hal ini maka diperlukan Arduino Uno kedua yang menyimpan library MFRC522 sehingga bisa menjembatani komunikasi dengan modul RFID Reader.

Ada dua software yang dikembangkan,yaitu server Node.js, berupa skrip dan aplikasi Arduino. Skrip Node.js dijalankan pada terminal / Command Prompt sistem operasi. Hampir semua sistem operasi yang ada sekarang ini mendukung platform Node.js, diantaranya adalah sistem operasi Linux, Unix, Mac OS dan Windows. Secara umum server Node.js memiliki dua tugas utama, yaitu sebagai pusat komunikasi sistem dan sebagai pengolah data. Gambar 2 adalah diagram sistem komunikasi yang dipakai dalam penelitian ini:

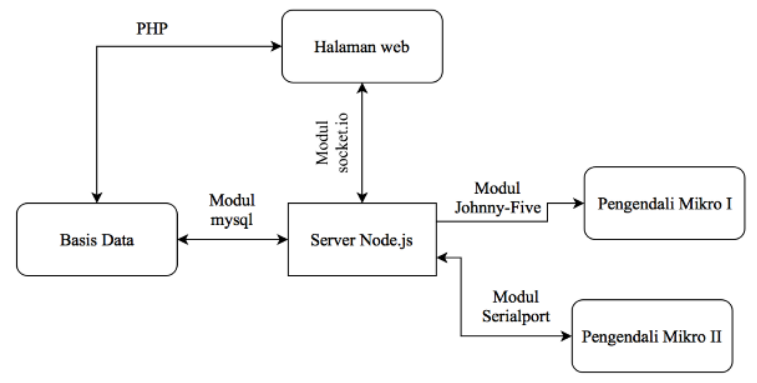

Gambar 2. Diagram Sistem Komunikasi

Adapun komunikasi yang dikelola oleh server Node.js antara lain: Pertama, komunikasi antara server dan halaman web dengan menggunakan modul Node.js bernama Socket.io. Socket.io merupakan modul Node.js, yang menggunakan protokol komunikasi 
WebSocket. Kedua, komunikasi antara server dan basis- Sebagai contoh, bila skrip menerima instruksi dari data dengan menggunakan modul mySQL. Modul ini halaman web (website), maka skrip melakukan proses merupakan implementasi MySQL pada Node.js, untuk meneruskan instruksi tersebut ke Arduino secara sehingga syntaxes yang digunakan pada modul ini sama terus menerus (seperti digambarkan oleh diagram yang dengan syntaxes pada MySQL. Ketiga, sedangkan untuk tidak terdapat end). komunikasi antara server dan mikrokontroler Arduino yang pertama, modul Johnny-Five digunakan sebagai media untuk menjembatani komunikasi tersebut. Modul ini merupakan framework berbasis Firmata, yang berfungsi untuk mempermudah komunikasi antara Node.js dan mikrokontroler Arduino. Firmware Firmata harus diunduh dan disimpan dalam memory Arduino, untuk penggunaan modul tersebut adalah dengan melalui akses yang sudah tersedia pada Arduino IDE. Keempat, modul serialport digunakan untuk komunikasi antara server dan mikrokontroler Arduino yang kedua. Modul ini digunakan, karena perbedaan jenis komunikasi yang ada pada mikrokontroler Arduino pertama, yang sudah menyimpan firmware Firmata, dan tidak mendukung library MFRC522. Sehingga modul serialport ditambahkan untuk mengatasi hal tersebut. Modul serialport menerima data dari port serial, sehingga data yang dikirimkan oleh mikrokontroler Arduino yang kedua, melalui serial port, diterima oleh server Node.js.

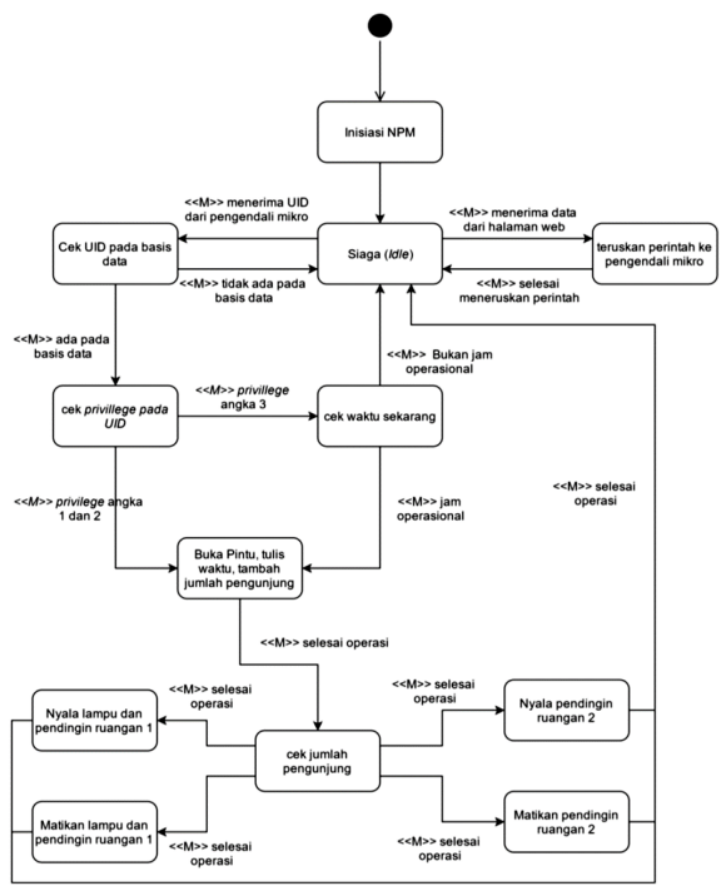

Gambar 3. Diagram cara kerja skrip server Node.js

Diagram kerja skrip server Node.js bisa dilihat pada Gambar 3. Ketika skrip dijalankan, maka skrip melakukan inisiasi modul, yaitu modul NPM. Kemudian skrip memasuki fase event-loop, event ditandai dengan munculnya bentuk bangun duadimensi yang berbingkai lebih tebal, lalu skrip melakukan instruksi sesuai dengan event yang terjadi.
Tahap pemasangan Node.js, pertama unduh installer Node.js pada halaman web resmi Node.js yaitu https://nodejs.org/en/download/, lalu unduh installer sesuai dengan pada sistem operasi yang ada di komputer. Pada penelitian ini digunakan sistem operasi Windows 64-bit, maka, installer yang diunduh adalah installer Windows 64-bit. Untuk lebih jelas dapat dilihat pada Gambar 4.

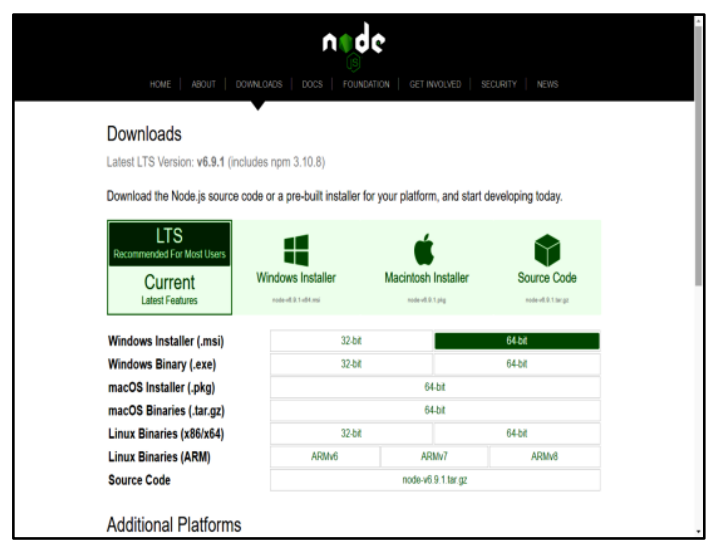

Gambar 4. Pemasangan Node.js

Setelah installer berhasil diunduh, kemudian dilakukan proses instalalisasi hingga selesai. Lalu dilakukan pengujian apakah Node.js telah terpasang dengan baik, dengan mengetikan "node $-v$ " pada aplikasi Command Prompt. Jika Node.js telah terpasang dengan benar maka Command Prompt mengembalikan keluaran yang berisi versi dari Node.js yang terpasang. Hasil keluaran terlihat pada Gambar 5.

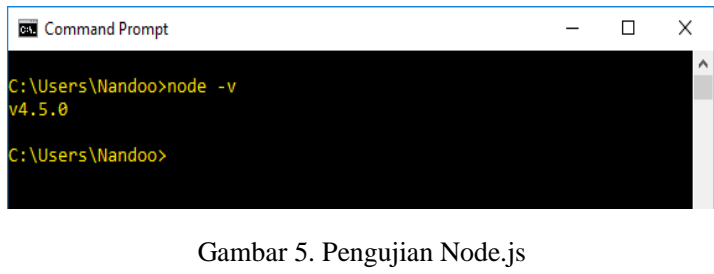

Environment dari Node.js dikelompokkan dalam bentuk project yang ditempatkan pada suatu berkas/folder. Sehingga setelah sebuah nama folder dibuat, kemudian buka aplikasi Command Prompt dan tujukan Command Prompt pada folder ini dengan cara menahan tombol shift pada keyboard dan klik kanan pada folder project, klik pilihan "open command window here" pada menu drop-down yang muncul. Untuk lebih jelas dapat dilihat pada Gambar 6.

Jurnal RESTI (Rekayasa Sistem dan Teknologi Informasi) Vol . 1 No. 1 (2017) 50 - 57 


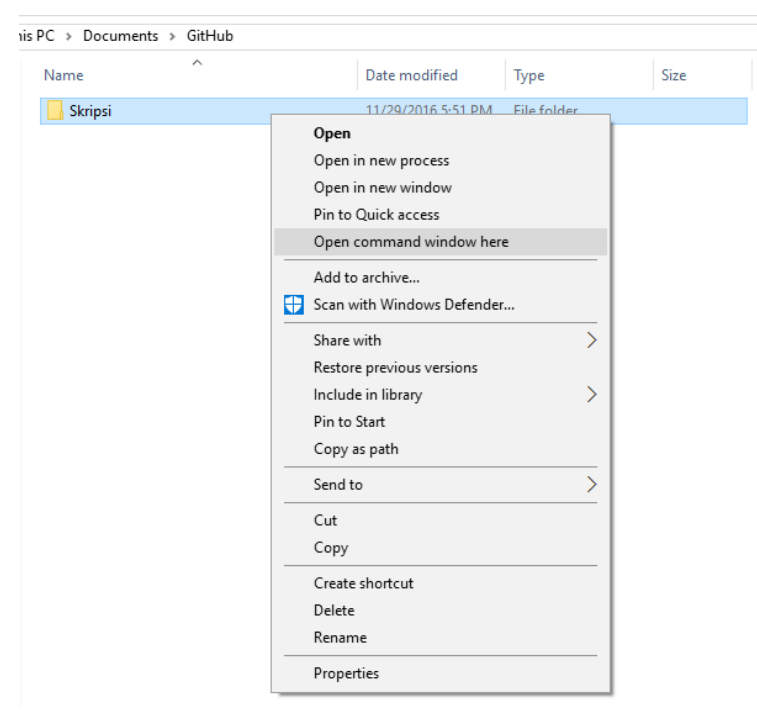

Gambar 6. Menu Dropdown

Setelah itu, terbuka aplikasi Command Prompt yang tertuju pada berkas proyek, lalu ketikan perintah berikut pada Command Prompt "npm install johnnyfive mysql serialport socket.io”. Maka NPM (Node Package Module) memasang empat modul yang tertera pada perintah. Pastikan komputer terhubung ke internet, karena NPM memerlukan koneksi internet untuk melakukan pemasangan modul. Setelah selesai, Command Prompt memberitahukan pada keluaran yang menyatakan pemasangan berhasil.

Berikut cara memasang firmware Firmata, pada mikrokontroler Arduino yang pertama, sambungkan mikrokontroler ke komputer, lalu buka aplikasi Arduino IDE. Jika aplikasi belum terpasang, maka installer aplikasi dapat diperoleh di halaman resmi Arduino di https://www.arduino.cc/en/Main/Software. Lalu pilih menu file > example > Firmata > StandardFirmata. Maka terbuka source code StandardFirmata. Kemudian upload source code tersebut ke Arduino dengan menekan tombol upload. Pemasangan Firmware Firmata, pada mikrokontroler Arduino yang pertama, selesai.

Sambungkan mikrokontroler Arduino yang kedua ke komputer, melalui kabel usb-to-serial. Pilih menu, file $>$ open >, lalu tujukan ke berkas yang telah di unduh. Buka berkas "Arduino", di dalamnya terdapat source code bernama "rfid.ino". Klik dua kali file tersebut. Kemudian unggah source code tersebut dengan menekan tombol upload. Pemasangan source code Arduino, pada mikfrokontroler Arduino yang kedua, selesai. Aplikasi Arduino, yang dipasang pada mikrokontroler Arduino yang kedua, berfungsi untuk membaca numeric didalam kartu RFID (smart card), yang dimiliki oleh pengunjung lab, melalui $R F I D$ Reader.

Basis data, secara keseluruhan, terdiri dari sebuah basis data bernama "siskomlab" dengan empat buah table, yaitu tabel buku tamu, tabel pengunjung terdaftar, tabel login halaman web dan tabel jumlah pengunjung.

Tabel Buku Tamu, berfungsi seperti layaknya buku tamu yang biasa digunakan, berisikan nama pengunjung, dan rekam waktu masuk/keluar ruang lab. Contoh tabel dapat dilihat pada Tabel 1, Tabel 2, dan Tabel 3.

Tabel 1. Tabel Buku Tamu -1

\begin{tabular}{|l|l|l|}
\hline UID & Jam masuk & Jam keluar \\
\hline 2322723052 & $2016-10-1216: 50: 15$ & $2016-10-12$ 16:50:19 \\
\hline 2525118514 & $2016-10-1216: 50: 26$ & $2016-10-1216: 50: 33$ \\
\hline
\end{tabular}

Tabel 2. Tabel Buku Tamu -2

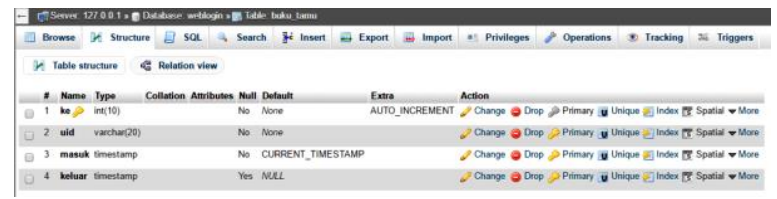

Secara keseluruhan:

Tabel 3. Tabel Buku Tamu -3

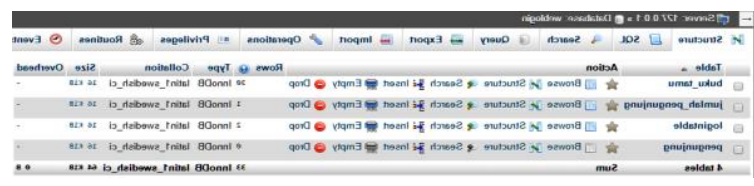

Tabel pengunjung terdaftar berisikan pengunjung (mahasiswa), penanggung jawab ruang lab, dan dosen yang telah terdaftar atau dengan kata lain orang yang memiliki izin untuk masuk dan keluar ruang lab. Hanya orang yang tercatat pada tabel ini yang dapat masuk/keluar ruang lab. Tabel terdiri dari empat kolom yaitu kolom nama, UID, privillege, dan status. Kolom nama berisi nama pengunjung, kolom UID berisi kode identitas dari pengunjung tersebut, kolom privilege atau dalam bahasa Indonesia berarti hak istimewa, berisikan angka antara satu sampai tiga. Kolom terakhir adalah kolom status yang berupa angka antara nol atau satu. Angka ini menandakan status posisi pengunjung, angka satu berarti pengunjung sedang berada di dalam lab, angka nol berarti pengunjung sedang berada di luar lab. Format tabel dapat dilihat pada contoh Tabel 4 dan Tabel 5.

Tabel 4. Tabel Pengujung Terdaftar -1

\begin{tabular}{|l|l|l|l|}
\hline Nama & UID & Privilege & Status \\
\hline Andre Young & 10628203226 & 1 & 0 \\
\hline Pak Arnold & 2322723052 & 3 & 0 \\
\hline
\end{tabular}

Tabel 5. Tabel Pengujung Terdaftar -1

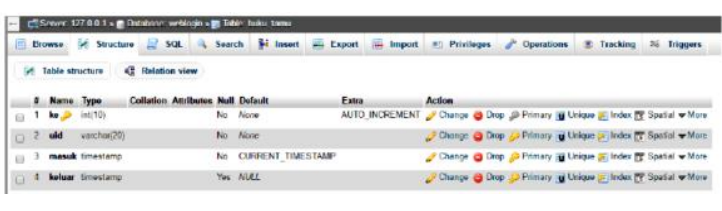

Jurnal RESTI (Rekayasa Sistem dan Teknologi Informasi) Vol. 1 No. 1 (2017) 50 - 57 
Tabel login halaman web, berisi para pengguna Implementasi privilege pada system dengan aturan halaman web, yang memiliki izin untuk melakukan sebagai berikut: aturan pertama, hanya pengunjung login ke halaman web. Tabel terdiri dari dua buah yang terdaftar pada "Tabel Pengunjung Terdaftar" yang kolom, kolom pertama pada basis data bernama kolom mendapatkan izin dari sistem untuk masuk ruang lab. user berisi nama pengguna halaman web, dan kolom Aturan kedua, penentuan jam operasional lab pada hari kedua pada basis data bernama pass berisi kata sandi Senin-Jumat pukul 07:00-16:00, di luar jam operasional atau password dari pengguna yang bersangkutan. hanya pengunjung terdaftar dengan privilege angka tiga Untuk lebih jelas dapat dilihat pada Tabel 6 dan Tabel dan dua yang bisa memasuki ruang lab. Ketentuan 7.

Tabel 6. Tabel Login -1

\begin{tabular}{|c|c|}
\hline user & pass \\
\hline admin & 1122334455667788 \\
\hline nandoo & bulan \\
\hline
\end{tabular}

Tabel 7. Tabel Login -2

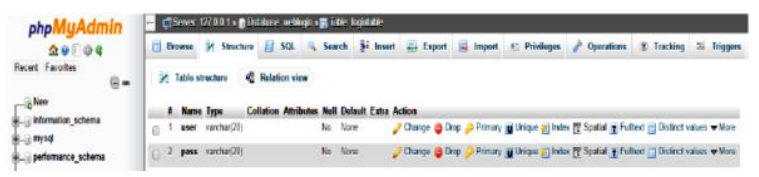

Sebagai contoh, pada baris pertama, nama pengguna bernama "admin" dan memiliki kata sandi “1122334455667788".

Tabel jumlah pengunjung berisikan jumlah pengunjung yang sedang berada di dalam lab. Tabel hanya terdiri dari satu kolom yaitu kolom "jumlah". Pada basis data tabel dinamakan "jumlah_pengunjung" yang dapat dilihat pada Gambar 7.

Gambar 7. Jumlah_Pengunjung

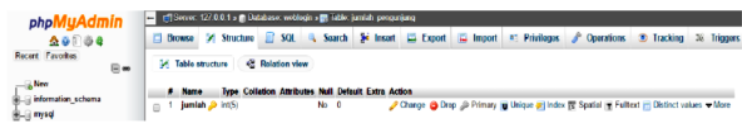

Sistem ini juga di rancang untuk melayani privilege, pelayanan sebuah privilege harus dilengkapi dengan rules atau aturan. Berikut adalah penjelasan arti angka pada kolom privilege dalam tabel pengunjung yang terdaftar, karena angka ini mempengaruhi aturan yang berlaku terhadap setiap pengunjung. Pada kolom privilege berisi angka satu sampai tiga. Angka tersebut menandakan nama pengunjung dan hak diberikan kepada pengunjung tersebut, arti angka-angka tersebut adalah angka satu berarti mahasiswa, angka dua berarti mahasiswa yang mendapat hak istimewa sementara, angka tiga berarti dosen atau asisten dosen. Dengan kata lain, "pengunjung angka satu" berarti yang dimaksudkan adalah pengunjung yang memiliki privilage tingkat satu, jika disebutkan "pengunjung angka dua" berarti yang dimaksudkan adalah pengunjung yang memiliki privilege tingkat dua, begitu juga untuk "pengunjung angka tiga" yang berarti pengunjung yang memiliki privilege tingkat tiga. aturan ke-tiga adalah ketika pengunjung yang terdaftar dengan privilege kode angka tiga dan dua memasuki ruang lab, lampu dan pendingin ruangan menyala secara otomatis jika kondisi awal dalam keadaan tidak menyala. Ketentuan aturan ke-empat adalah ketika ruang lab kosong, sistem dengan otomatis mematikan lampu dan pendingin ruangan. Ketentuan aturan kelima adalah ketika pengunjung lab berjumlah kurang dari sepuluh orang, hanya satu pendingin ruangan yang dinyalakan oleh sistem. Jika pengunjung lab berjumlah lebih dari sepuluh, sistem menyalakan dua buah pendingin ruangan.

Fungsi utama dari halaman web adalah melakukan interfacing / antarmuka pengolahan data, menampilkan data, dari basis data, dan antarmuka untuk operasi pengendalian perangkat kelistrikan secara langsung. Halaman web difungsikan secara sepsifik kepada penanggung jawab lab (asisten dosen) atau dosen yang bersangkutan. Halaman web dialokasikan pada Apache server yang beroperasi di komputer yang sama dimana mikrokontroler Arduino terhubung. Apache server yang digunakan, adalah dari installer XAMPP, yang merupakan aplikasi pemasangan yang di dalamnya terdapat Apache server, basis data MySql, bahasa skrip PHP dan Perl (dalam penelitian ini, bahasa skrip Perl tidak digunakan).

Tampilan halaman web dibuat dengan menggunakan framework Bootstrap. Semua tampilan, dari menu drop-down, judul, teks, dan tombol, menggunakan style default milik Bootstrap.

Untuk memungkinkan halaman web dapat mengolah data dari basis data digunakan skrip PHP. Selain digunakan untuk mengolah data, $P H P$ juga digunakan untuk menjaga keamaan halaman web. Salah satu fitur PHP yaitu sesssion yang berfungsi untuk mencatat sesi login pengguna halaman web, sehingga halaman web tidak dapat diakses oleh pengguna yang tidak melakukan login. Halaman login dapat dilihat pada Gambar 8 .

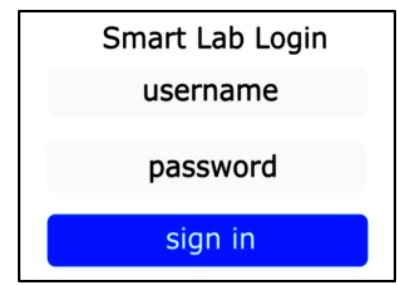

Gambar 8. Prototipe Sistem Yang Dirancang

Jurnal RESTI (Rekayasa Sistem dan Teknologi Informasi) Vol . 1 No. 1 (2017) 50 - 57 
Halaman login, dimana penanggung jawab lab atau Halaman "Tambah Pengunjung” yang berguna untuk dosen yang bersangkutan melakukan login. menambahkan pengunjung atau member baru ke basis Halaman "Depan", berisi fungsi dan fitur dari halaman data. Penambahan pengunjung dilakukan dengan web. Pada bagian atas terdapat navigation bar yang memasukan nama pengunjung pada textbox yang merupakan header navigasi dari halaman web, karena disediakan dan pada textbox "uid" akan secara otomatis fungsinya sebagai navigasi sehingga posisi navigation terisi ketika penanggung jawab lab mendekatkan atau bar bersifat persistant yang berarti navigation bar tetap scan kartu yang disediakan untuk pengunjung atau ada pada setiap halaman web kecuali halaman login, member baru yang akan didaftarkan. Rancangan berisi tombol - tombol link yang mengarah ke halaman halaman "Tambah Pengunjung" dapat dilihat seperti - halaman lain, selain itu juga terdapat tombol untuk Gambar 11.

melakukan logout. Kemudian di bagian bawah navigation bar terdapat gambar, isi gambar adalah gambar yang bertema smart laboratorium. Gambar ini bertujuan untuk memperindah halaman "Depan". Kemudian, dilanjutkan dengan ringkasan fungsi dan fitur halaman web, yang dilengkapi dengan beberapa screenshot halaman web. Untuk tampilan halaman peralatan dapat dilihat pada Gambar 9.

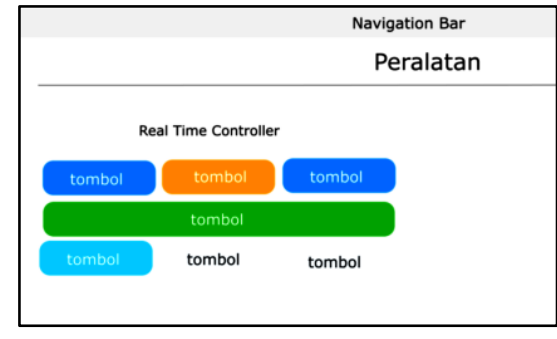

Gambar 9. Tampilan Halaman Peralatan

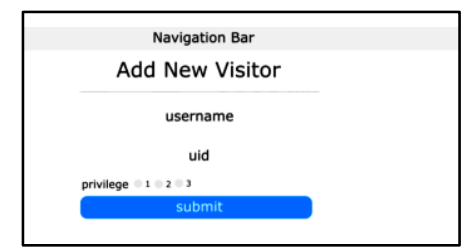

Gambar 11. Tampilan Halaman Tambah Pengujung

Dalam hal sistem keamanan halaman web, untuk penelitian ini, salah satu fitur dari $p h p$ yang digunakan adalah session. Sehingga halaman web hanya bisa diakses ketika pengguna halaman web telah melakukan login. Jika pengguna halaman web tidak melakukan login, dan mencoba untuk mengakses halaman tertentu, maka pengguna halaman web diarahkan ke halaman login. Fitur session diterapkan pada semua halaman web, kecuali halaman login.

Halaman "Peralatan" atau tools berisikan judul Gambar keseluruhan sistem hardware yang sudah halaman, lalu pada bagian tengah berisi tombol terintegrasi dapat dilihat pada Gambar 12.

pengendali perangkat kelistrikan, sehingga pengguna dapat menyalakan atau mematikan perangkat secara langsung. Terdapat juga tombol yang mengarahkan ke phpMyAdmin, sebuah tools yang digunakan untuk pengolahan basis data.

Halaman "Data Pengunjung" berisi judul halaman, di bagian tengah terdapat dua buah tabel yang bersampingan, dan di bagian bawah terdapat tombol untuk memanipulasi data pada tabel pengunjung. Tabel pertama berisi data pengunjung berupa waktu rinci masuk dan keluar lab, tabel kedua berisi pengunjung yang terdaftar.

Halaman "Bagaimana Cara" pada bagian atas terdapat judul halaman, kemudian di bawah judul terdapat penjelasan menggunakan halaman web. Rancangan halaman "Bagaimana Cara" dapat dilihat pada Gambar 10 .

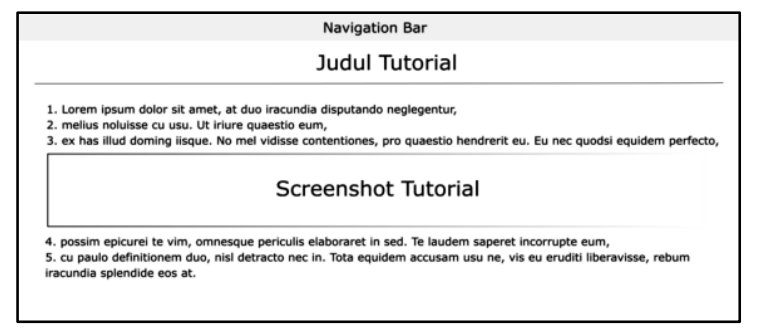

Gambar 10. Tampilan Halaman Bagaimana Cara

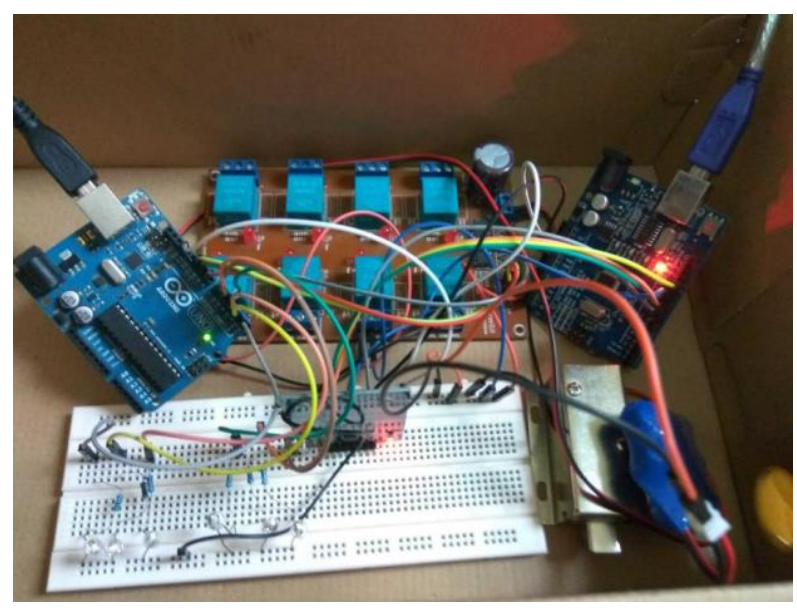

Gambar 12. Keseluruhan Sistem Hardware

Dalam proses implementasi software perlu diingat pada saat installer Node.js melakukan pemasangan, tidak hanya platform Node.js yang terpasang, tetapi installer juga memasang aplikasi NPM (Node Package Module) yang berfungsi untuk pemasangan modul Node.js.

Pada sistem yang dibangun memiliki tiga macam pengunjung yang memiliki privilege tertentu, maka setiap jenis privilege pengunjung diuji dengan empat jenis pengujian sehingga total pengujian terdapat 12

Jurnal RESTI (Rekayasa Sistem dan Teknologi Informasi) Vol . 1 No. 1 (2017) 50 - 57 
jenis pengujian. Setiap jenis pengujian dilakukan pengujian secara keseluruhan. Terdapat dua belas jenis sebanyak 30 kali. Hasil dari pengujian ditampilkan pengujian yang masing-masing dilakukan sebanyak 30 pada tabel berikut dibawah ini. Dari hasil keseluruhan kali.

didapatkan nilai rata-rata keberhasilan sebesar $94 \%$ dan kegagalan sebesar 6\%. Kegagalan yang terjadi 5.2 Saran diakibatkan oleh bug yang terdapat pada modul Node.js serialport. Modul terkadang tidak merespon atau memberikan respon terlambat. Tabel hasil pengujian dapat dilihat pada Tabel 9.

Dari kesimpulan di atas, ada beberapa saran yang dapat diterapkan untuk mengembangkan penelitian ini. Diantaranya, yaitu memperbanyak variasi perangkat kelistrikan yang dapat dikendalikan, seperti kipas angin dan projector. Kemudian mengintegrasikan dengan sistem lain, terutama sistem yang menggunakan

Tabel 9. Tabel Hasil Pengujian

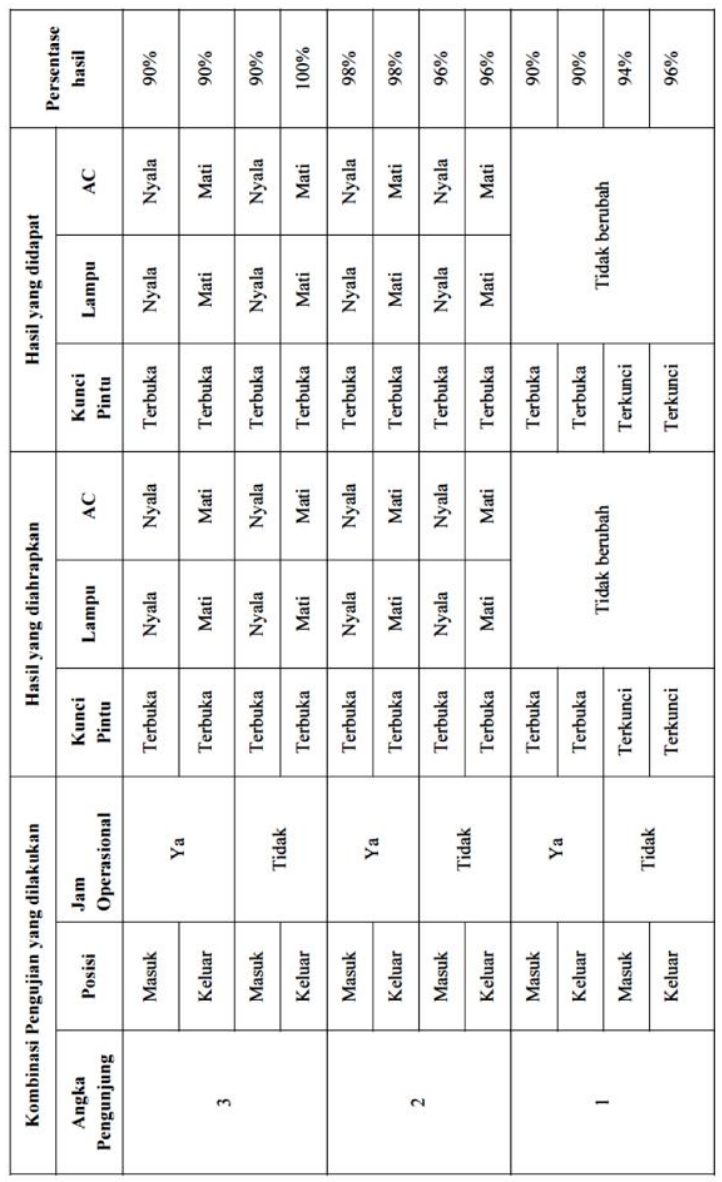

\section{Kesimpulan}

\subsection{Simpulan}

Telah dibuat purwarupa sistem pendataan pengunjung dengan mencatat waktu masuk/keluar pengunjung dan pengendalian perangkat kelistrikan laboratorium yaitu pendingin ruangan, lampu, dan kunci pintu dengan mengimplementasi aturan yang didefinisikan. Sistem Pendataan Pengunjung telah berhasil mencatat data pengunjung meliputi nama pengunjung, waktu masuk/keluar pengunjung ke laboratorium. Sistem Pengendalian Peralatan Kelistrikan Laboratorium telah mampu mengendalikan lampu $12 \mathrm{~V}$, relay dan kunci pintu solenoid. Hasil pengujian sistem secara keseluruhan diperoleh persentase keberhasilan sebesar 94\%. Hasil ini didapat dengan merata -rata nilai hasil Node.js dan berhubungan dengan Internet of Things, seperti sistem pengunci loker elektronik.

\section{Daftar Rujukan}

[1] Tanenbaum, A., 2014. Computer networks. 6th ed. Upper Saddle River, NJ: Prentice Hall PTR.

[2] Rai, R., 2013. Socket.io Real-time Web Application Development. 1st ed. Birmingham: Packt Pub.

[3] Internet of things agenda. Rouse, M. RFID (radio frequency identification). Updated April 2007. Available at: http://internetofthingsagenda.techtarget.com/definition/RFIDradio frequency-identification. [Accessed: Nov. 14, 2016].

[4] Northwestern University Mechatronics Design Laboratory, 2006. Available at: http://mechatronics.mech.northwestern.edu. [Accessed: Nov. 14, 2016]

[5] Github. Firmata Protocol Documentation. Available at: https://github.com/firmata/protocol. [Accessed: Nov. 14, 2016]

[6] Chaniotis, I.K., Kyriakou, K.I.D., Tselikas, N.D., 2015. Is Node.js a viable option for building modern web applications? A performance evaluation study. Springer

[7] M Cantelon, M Harter, TJ Holowaychuk, N Rajlich. 2014. Node.js in Action. Available at: toc.dreamtechpress.com

[8] Daggett, M.E., 2013. JavaScript IRL. Springer

[9] Node.js Foundation, 2016. Working with Different Filesystems. Available at: https://nodejs.org/en/docs/guides/working-withdifferent-filesystems [Accessed: Nov. 14, 2016]

[10] Standard ECMA-414. 2016. ECMAScript Specification Suite $.2^{\text {nd }}$ ed. Available at: https://www.ecmainternational.org/publications/standards/Ecma-414.htm [Accessed: Nov. 16, 2016]

[11] Bell, C., 2014. MySQL High Availability: Tools for Building Robust Data Centers. $2^{\text {nd }}$ ed. Sebastopol, CA: O’Reilly Media.

[12] Skvorc, Bruno, 2015. $1^{\text {st }}$ ed. Jump Start PHP Environment.Collingwood, Australia: SitePoint Pty.

[13] Lombardi, Andrew, 2015. $1^{\text {st }}$ ed. Websocket. Sebastopol, CA: O'Reilly Media.

[14] Frenzel, Louis., 2016. Handbook of Serial Communication Interfaces. Waltham, MA: Elsevier.

[15] Henderson, H., 2016. Encyclopedia of computer science and technology $.2^{\text {nd }}$ ed. New York, NY: Facts On File

[16] Firmata Library. 2016. Available at: https://www.arduino.cc/en/Reference/Firmata [Accessed: Nov.14, 2016] 